\title{
Annoyance caused by the sounds of a magnetic levitation train
}

\author{
Joos Vos ${ }^{a)}$ \\ TNO Human Factors, P.O. Box 23, 3769 ZG Soesterberg, The Netherlands
}

(Received 25 April 2003; accepted for publication 5 January 2004)

\begin{abstract}
In a laboratory study, the annoyance caused by the passby sounds from a magnetic levitation (maglev) train was investigated. The listeners were presented with various sound fragments. The task of the listeners was to respond after each presentation to the question: "How annoying would you find the sound in the preceding period if you were exposed to it at home on a regular basis?" The independent variables were (a) the driving speed of the maglev train (varying from 100 to 400 $\mathrm{km} / \mathrm{h}$ ), (b) the outdoor A-weighted sound exposure level (ASEL) of the passbys (varying from 65 to $90 \mathrm{~dB}$ ), and (c) the simulated outdoor-to-indoor reduction in sound level (windows open or windows closed). As references to the passby sounds from the maglev train (type Transrapid 08), sounds from road traffic (passenger cars and trucks) and more conventional railway (intercity trains) were included for rating also. Four important results were obtained. Provided that the outdoor ASELs were the same, (1) the annoyance was independent of the driving speed of the maglev train, (2) the annoyance caused by the maglev train was considerably higher than that caused by the intercity train, (3) the annoyance caused by the maglev train was hardly different from that caused by road traffic, and (4) the results (1)-(3) held true both for open or closed windows. On the basis of the present results, it might be expected that the sounds are equally annoying if the ASELs of the maglev-train passbys are at least $5 \mathrm{~dB}$ lower than those of the intercity train passbys. Consequently, the results of the present experiment do not support application of a railway bonus to the maglev-train sounds. (C) 2004 Acoustical Society of America. [DOI: 10.1121/1.1650330]
\end{abstract}

PACS numbers: 43.50.Ba, 43.50.Lj, 43.50.Qp [DKW]

Pages: $1597-1608$

\section{INTRODUCTION}

Magnetic levitation (maglev) trains utilize an advanced technology in which magnetic forces lift, propel, and guide the vehicle over a guideway. The technology permits maximum speeds of up to about $500 \mathrm{~km} / \mathrm{h}$, which is almost twice as high as that of conventional high-speed trains. Because of its high speed, the maglev train is able to compete with auto and aviation modes for travel distances between about 75 and $1000 \mathrm{~km}$, and is therefore an interesting travel option for the 21 st century.

Test tracks of the maglev train have been built in Japan, Germany, and China. In the USA there are currently no maglev systems in operation, although there are several corridors that have been studied in detail and that are awaiting funding decision by the Federal Railroad Administration. ${ }^{1}$ For some of these projects environmental impact statements are being prepared.

Similarly, in the interest of improving the infrastructure of the Northern part of The Netherlands, an intelligent choice among various alternative measures required detailed knowledge about the annoyance caused by the passby sounds from a maglev train. Since at least in Europe, there are at present no tracks of the maglev train located in or close to residential areas, a field survey could not be carried out. Consequently, the research was performed in the laboratory.

Some data on overall loudness (rather than annoyance) of passby sounds of a maglev train (type Transrapid 07) and more conventional trains (types EC, IC, ICE, and a freight train) have been reported by Fastl and Gottschling (1996)

${ }^{\text {a)} E l e c t r o n i c ~ m a i l: ~ v o s @ t m . t n o . n l ~}$ and by Gottschling and Fastl (1997). In these two related laboratory studies, the overall (or global) loudness ratings for the maglev and more conventional train sounds presented at comparable A-weighted equivalent sound levels were not significantly different.

In a laboratory study reported by Neugebauer and Ortscheid (1997), the overall loudness and other subjective evaluations were determined for passages of a maglev train and a conventional short-range train. For three relevant factors (evaluation, activity, and potency) summarizing the responses obtained with the method of the semantic differential, the sounds of the maglev train yielded significantly higher values than those of the short-range train, indicating that, overall, the subjects were more negative about the maglev train. Moreover, especially at the higher A-weighted equivalent sound levels, the sounds from the maglev train were considerably louder than those of the short-range train.

Results on a semantic study of acoustic and nonacoustic aspects in the evaluation of maglev and short-range train passby sounds have also been reported by Quehl (1999). The limited number of experimental conditions and imperfections in a portion of the passby sounds, however, prevented her from drawing firm conclusions.

In sum, the available data on the subjective evaluation of maglev-train sounds are limited, and the results are inconsistent: The results described in Fastl and Gottschling (1996) and in Gottschling and Fastl (1997) suggest that the railway bonus for conventional trains might also be applied to the maglev train, whereas the results from Neugebauer and 
Ortscheid (1997) might indicate that application of the bonus to the maglev train is not permitted.

In the present laboratory study, listeners had to rate the annoyance of various sound fragments. With respect to the validity of the experimental results obtained in laboratory studies, our experiences are positive. For example, differences in annoyance between road-traffic sounds and shooting sounds produced by small firearms, as found in field surveys, are obtained in laboratory studies also (Vos, 1995).

One of the independent variables in the present study was the driving speed of the maglev train (varying from 100 to $400 \mathrm{~km} / \mathrm{h}$ ). Since most environmental noise ordinances are based on sound levels measured outside residences, the second independent variable was the outdoor A-weighted sound exposure level (ASEL) of the passbys (varying from 65 to 90 $\mathrm{dB}$ ). The annoyance inside the dwelling furthermore depends on the attenuation of the facade structure. As a result, the third independent variable was the simulated outdoor-toindoor reduction in sound level (windows open or windows closed). As references to the sounds from the maglev train (type Transrapid 08), sounds from road traffic (passenger cars and trucks) and more conventional railway (intercity trains) were included for rating also.

\section{METHODS}

\section{A. Sound fragments}

The stimuli were sound passages of a maglev train, various intercity trains, a high-speed train, and various passenger cars and trucks. For all passages, free-field digital recordings were made.

The sounds of the maglev train (type Transrapid 08) were recorded in Lathen, Germany (de Graaff et al., 2001). We selected passages at four driving speeds $(100,200,325$, and $400 \mathrm{~km} / \mathrm{h}$ ), each passage being simultaneously recorded at three distances of 25, 50, and $100 \mathrm{~m}$. From these 12 recordings, 16 different sound fragments were prepared. Each fragment consisted of one passage with a duration of 15-20 s. Since the total duration of all fragments included in the present study was fixed at $45 \mathrm{~s}$, the maglev-train passages were preceded and followed by silent periods of about $12-15$ s. A realistic presentation of the fragments requires that, given a specific distance between the source and the receiver, the sound level at which a passage is reproduced in the laboratory does not significantly deviate from the level found in the field. A satisfactory representativeness was obtained by presenting the passages with driving speeds of 100 and 200 $\mathrm{km} / \mathrm{h}$ at outdoor ASELs of $65-80 \mathrm{~dB}$, and those with driving speeds of 325 and $400 \mathrm{~km} / \mathrm{h}$ at outdoor ASELs of 75-90 dB.

For the passages with driving speeds of 100 and 200 $\mathrm{km} / \mathrm{h}$ that were presented at the ASELs of 65 and $70 \mathrm{~dB}$, as well as for the passages with driving speeds of 325 and 400 $\mathrm{km} / \mathrm{h}$ that were presented at the ASELs of 75 and $80 \mathrm{~dB}$, the sounds recorded at a distance of $100 \mathrm{~m}$ were used. For the passages with driving speeds of 100 and $200 \mathrm{~km} / \mathrm{h}$ presented at an ASEL of $75 \mathrm{~dB}$, and for those with driving speeds of 325 and $400 \mathrm{~km} / \mathrm{h}$ presented at an ASEL of $85 \mathrm{~dB}$, the recordings at a distance of $50 \mathrm{~m}$ were used. For the remaining passages presented at an ASEL of $80 \mathrm{~dB}$ (driving speeds of
100 and $200 \mathrm{~km} / \mathrm{h}$ ) or for those presented at an ASEL of 90 $\mathrm{dB}$ (driving speeds of 325 and $400 \mathrm{~km} / \mathrm{h}$ ), the sounds recorded at a distance of $25 \mathrm{~m}$ were used.

The fragments of the intercity trains were based on the sounds from passenger trains (types ICR/ICM and IRM/DD) recorded at distances of 35 and $100 \mathrm{~m}$. For the outdoor ASELs of 75,80 , and $85 \mathrm{~dB}$, the passages of train types ICR/ICM and IRM/DD recorded at a distance of $100 \mathrm{~m}$ were used. For the sound fragment presented at an outdoor ASEL of $90 \mathrm{~dB}$, a passage of train type IRM/DD recorded at a distance of $35 \mathrm{~m}$ was used. The driving speed of the various trains was estimated to range between 120 and $140 \mathrm{~km} / \mathrm{h}$. Again, each fragment consisted of one passage. The duration of a passage was equal to $25-30 \mathrm{~s}$.

The fragments of the high-speed train (type TGVAtlantic) were based on passages recorded at distances of 50 and $200 \mathrm{~m}$. The passage recorded at a distance of $200 \mathrm{~m}$ was presented at ASELs of 75 and $80 \mathrm{~dB}$. The passage recorded at a distance of $50 \mathrm{~m}$ was presented at ASELs of 85 and 90 $\mathrm{dB}$. The driving speed of the train was equal to about 300 $\mathrm{km} / \mathrm{h}$.

The fragments of road traffic were based on the sounds from passenger cars and trucks recorded at distances of 12.5-60 $\mathrm{m}$ from a provincial road. The driving speed was equal to about $80 \mathrm{~km} / \mathrm{h}$. Each fragment consisted of partly overlapping passages of 10-12 different passenger cars and one truck, with a total duration of $45 \mathrm{~s}$. The maximum A-weighted levels of the truck passbys were about $10 \mathrm{~dB}$ higher than those of the passenger car passbys (Versfeld and Vos, 1997, 2002). The passages recorded at a distance of 60 $\mathrm{m}$ were presented at ASELs of 65 and $70 \mathrm{~dB}$. The passages recorded at a distance of $25 \mathrm{~m}$ were presented at ASELs of 75 and $80 \mathrm{~dB}$, and, for the sound fragments presented at an ASEL of $85 \mathrm{~dB}$, the recordings at a distance of $12.5 \mathrm{~m}$ were used.

The original sound recordings were further processed. To isolate the sound produced by a specific source from the background noise, the amplitude of the background noise was shaped over short time intervals of about $1 \mathrm{~s}$ just prior to the beginning (fade-in) and directly after the end (fade-out) of the audible source-specific sound. All traffic sounds were subjected to this way of processing. In some recordings of the maglev train, highly prominent bird singing was removed by filtering as much as possible. The passage of the highspeed train recorded at a distance of $200 \mathrm{~m}$ contained nonspecific low-frequency sounds. These sounds were removed with the help of a high-pass filter.

For each facade attenuation type, the level reduction is shown in Fig. 1. For the condition which simulated wideopen windows, an attenuation of $5 \mathrm{~dB}$ was assumed for frequencies between 12.5 and $1000 \mathrm{~Hz}$. For higher frequencies the attenuation was $8 \mathrm{~dB}$ at most. With the windows closed, the facade attenuation increased from $12 \mathrm{~dB}$ for the 16- and $31.5-\mathrm{Hz}$ octave bands up to $35 \mathrm{~dB}$ for the $8-\mathrm{kHz}$ octave band, and represented the average of noise attenuations that are frequently found for Dutch dwellings with the windows closed (Vos, 2001).

The sounds were reproduced in a relatively small listening room $\left(\mathrm{w} \times 1 \times \mathrm{h}=3.5 \times 5.9 \times 3.3 \mathrm{~m}^{3}\right)$. Specific resonance 


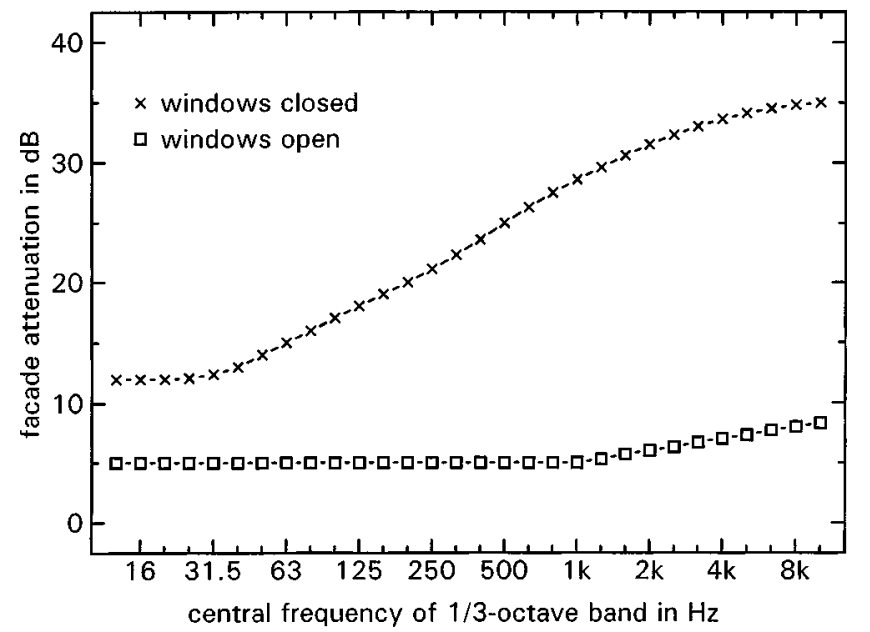

FIG. 1. Frequency-dependent outdoor-to-indoor sound reduction for two conditions.

frequencies (such as those around 30 and $60 \mathrm{~Hz}$ ) of the room, resulting in changes in the sound spectrum, as well as nonflat frequency characteristics of the audio equipment, were compensated as much as possible. Finally, for frequencies between 25 and $8000 \mathrm{~Hz}$, a flat frequency characteristic was obtained within about $4 \mathrm{~dB}$ (standard deviation of the deviations in the various $\frac{1}{3}$-octave bands equal to $2.6 \mathrm{~dB}$ ).

Spectra of the sound fragments were determined with the help of a Larson-Davis spectrum analyzer (Model 3200) and a Brüel \& Kjaer sound level meter (type 2236), with the microphone positioned at the ears of the subjects. The sound spectra are expressed as the linear sound exposure level in the various $\frac{1}{3}$-octave bands. The reference sound pressure is always equal to $20 \mu \mathrm{Pa}$. In the present report, spectra are shown in the condition which simulated wide-open windows only.

Figure 2 shows the linear sound exposure level in the various $\frac{1}{3}$-octave bands for the passages of the maglev train. For each driving speed four spectra are shown, corresponding to outdoor ASELs of $65,70,75$, or $80 \mathrm{~dB}$ for driving speeds of 100 and $200 \mathrm{~km} / \mathrm{h}$, and to outdoor ASELs of 75, 80,85 , or $90 \mathrm{~dB}$ for driving speeds of 325 and $400 \mathrm{~km} / \mathrm{h}$. Figure 2(a) shows a characteristic spectral peak around 315 $\mathrm{Hz}$ for the driving speed of $100 \mathrm{~km} / \mathrm{h}$. For a speed of 200 $\mathrm{km} / \mathrm{h}$ [Fig. 2(b)], such a peak is found around $630 \mathrm{~Hz}$. The spectral peak around $315 \mathrm{~Hz}$ for the driving speed of 100 $\mathrm{km} / \mathrm{h}$ and that around $630 \mathrm{~Hz}$ for the driving speed of 200 $\mathrm{km} / \mathrm{h}$ result from the groove passage frequency of stator grooves spaced at $0.083 \mathrm{~m}$ (de Graaff et al., 2001). Due to aerodynamic noise at the speeds of 325 [Fig. 2(c)] and 400 $\mathrm{km} / \mathrm{h}$ [Fig. 2(d)], the groove passage related frequency components do not longer determine the levels in the $\frac{1}{3}$-octave bands: Relevant spectral energy is found over a wide range between 100 and $2000 \mathrm{~Hz}$.

Figure 3 shows the four sound spectra for the intercity trains. In addition to the smaller spectral peak around 31.5 and $63 \mathrm{~Hz}$, a highly significant peak around $1600 \mathrm{~Hz}$ is obtained.

Figure 4 shows that the sounds of the high-speed train passbys contain very much energy up to frequencies of about 3-4 kHz. For frequencies between 25 and about $160 \mathrm{~Hz}$,

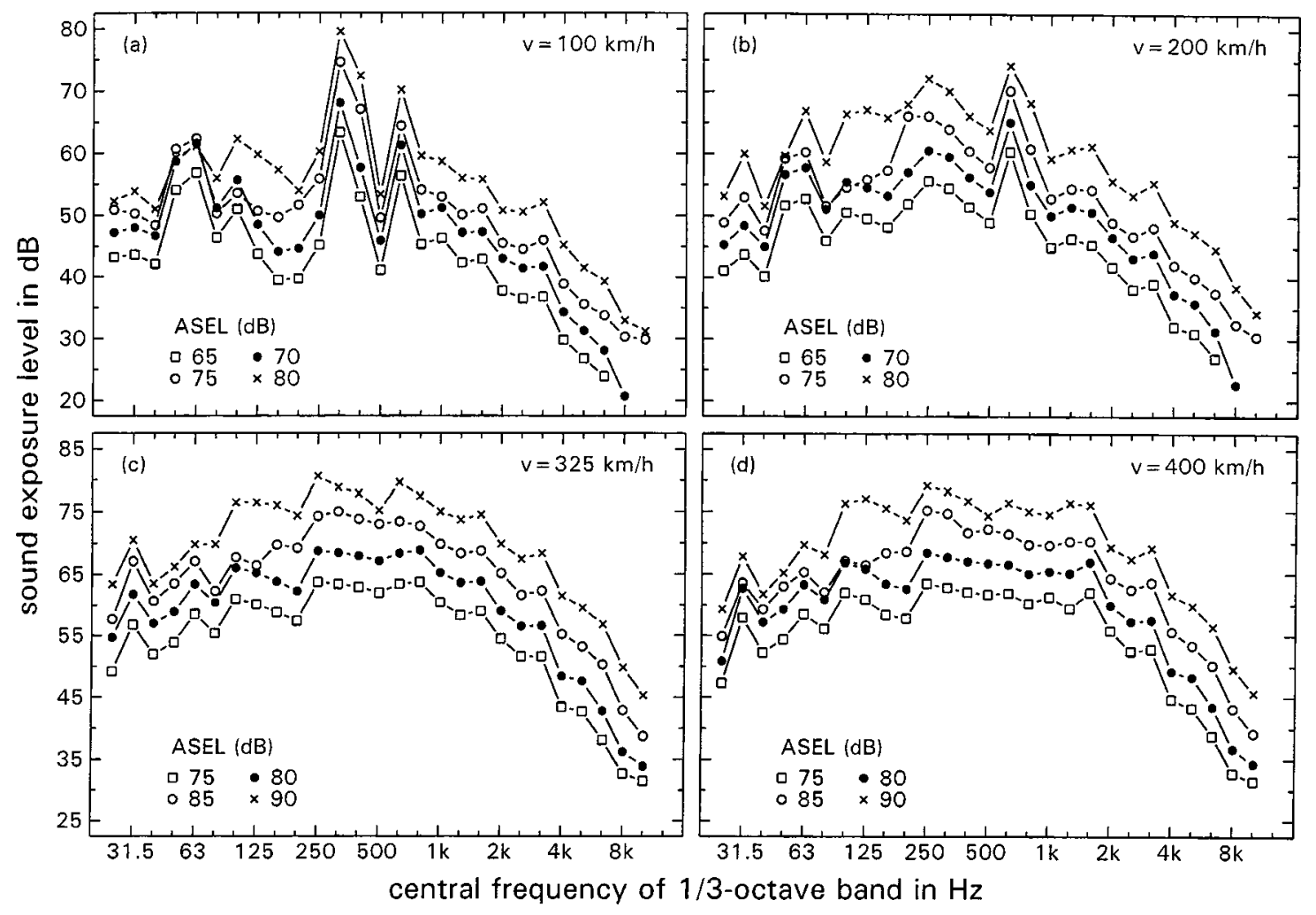

FIG. 2. Sound exposure levels in the various $\frac{1}{3}$-octave bands for four speeds of the maglev-train passbys, as determined at the ears of the subjects in the conditions which simulated open windows. For each driving speed, four spectra are shown with overall outdoor ASELs as indicated. Driving speed in km/h: (a) 100, (b) 200, (c) 325, and (d) 400 . 


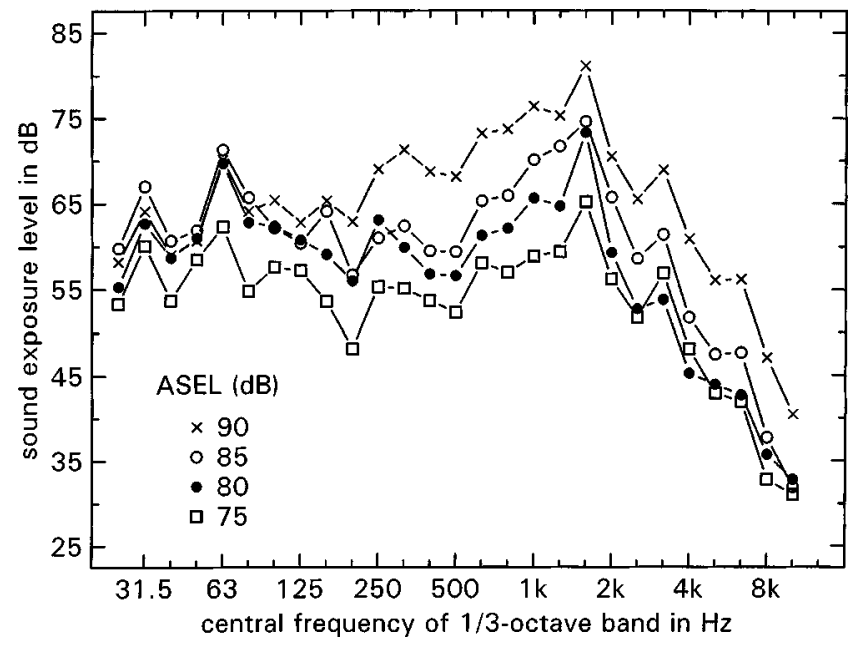

FIG. 3. Sound exposure levels in the various $\frac{1}{3}$-octave bands for intercitytrain passbys, as determined at the ears of the subjects in the conditions which simulated open windows. Four spectra are shown with overall outdoor ASELs as indicated.

large differences in sound level were obtained between the passby that was recorded at a distance of $50 \mathrm{~m}$ (ASELs of 85 and $90 \mathrm{~dB}$ ) and the passby that was recorded at a distance of $200 \mathrm{~m}$ (ASELs of 75 and $80 \mathrm{~dB}$ ). This difference must be the result of the high-pass filter that was used for "improving" the quality of the passby sound recorded at the larger distance of $200 \mathrm{~m}$. Apparently, the filtering had also affected the source-specific spectral content. As a result, the representativeness of the passby sounds presented at ASELs of 75 and $80 \mathrm{~dB}$ must be questioned.

Figure 5 shows three of the five spectra for the fragments with road-traffic sounds. Again, these sounds contain relatively much energy in a wide frequency range. A significant decrease in sound exposure level is found for frequencies higher than about $1600 \mathrm{~Hz}$.

In order to make the acoustic environment more realistic, a soft, spectrally shaped noise was continuously present throughout the experiment. In the condition which simulated

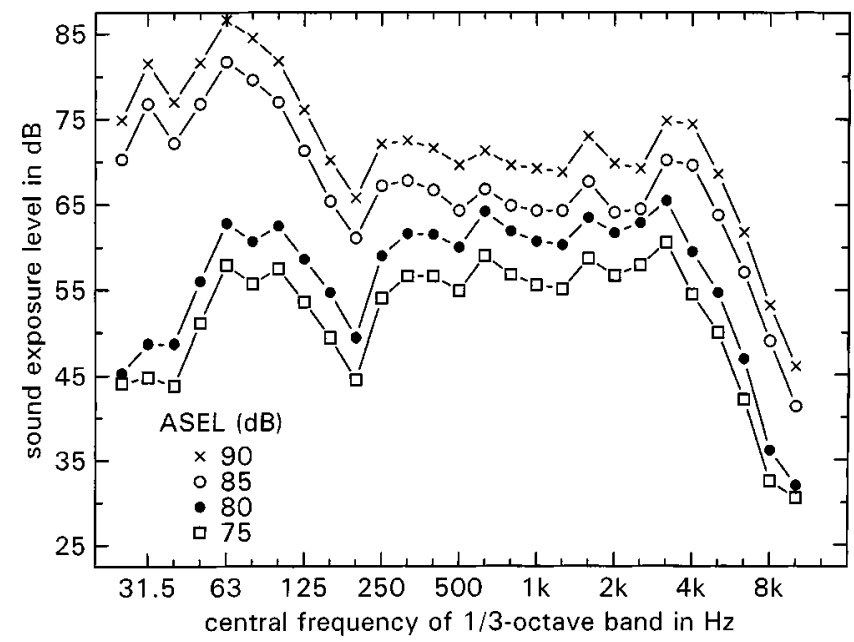

FIG. 4. Sound exposure levels in the various $\frac{1}{3}$-octave bands for high-speed train passbys, as determined at the ears of the subjects in the conditions which simulated open windows. Four spectra are shown with overall outdoor ASELs as indicated.

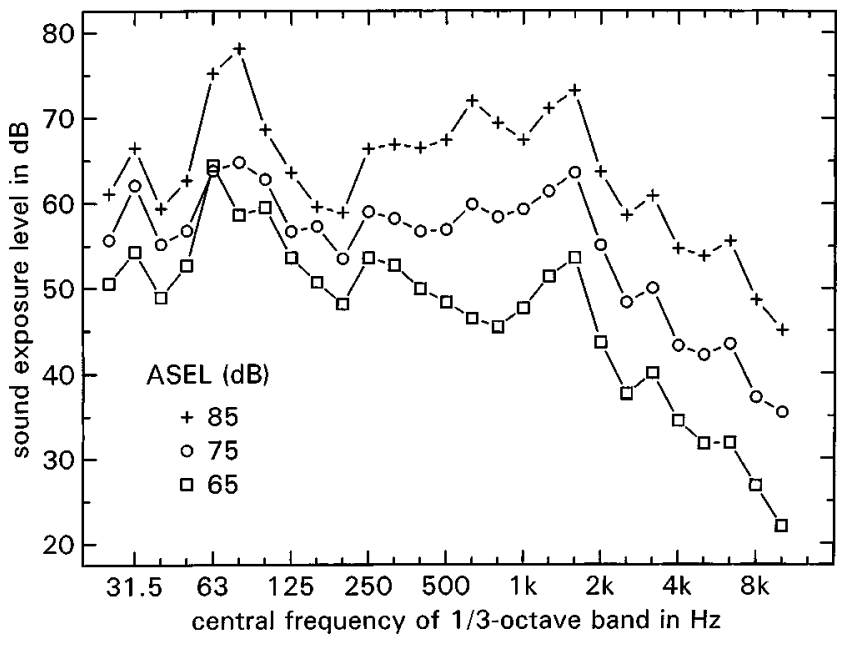

FIG. 5. Sound exposure levels in the various $\frac{1}{3}$-octave bands for road-traffic sounds, as determined at the ears of the subjects in the conditions which simulated open windows. Three of the five spectra are shown with overall outdoor ASELs as indicated.

open windows, the sound resembled traffic sounds as heard at a relatively great distance from a roadway. This background noise was presented at an A-weighted equivalent sound level of $35 \mathrm{~dB}$, measured at the ears of the subjects. In the condition which simulated closed windows, it was felt that the background noise should resemble the sounds from the central heating system or the ventilation system. To achieve this, the background noise was further subjected to an overall reduction in sound level and an additional attenuation of the low-frequency components. In the listening room, this background noise was presented at an A-weighted equivalent sound level as low as $29 \mathrm{~dB}$.

The spectra of the two background noise types are shown in Fig. 6. The binaural hearing threshold of otologically selected young listeners is inserted in the figure to emphasize that, in general, the sound components with frequencies lower than $63-100 \mathrm{~Hz}$ are no longer audible.

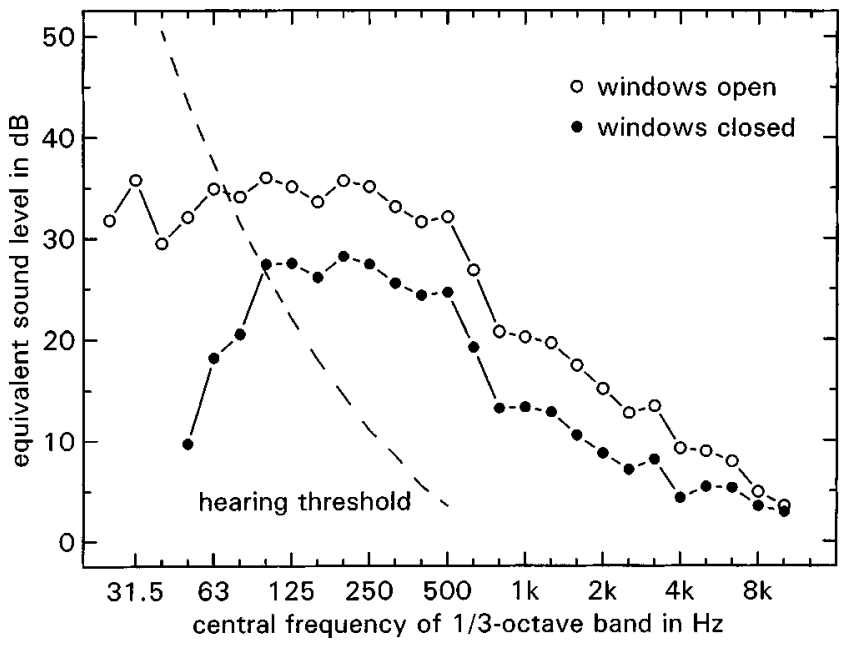

FIG. 6. Linear weighted equivalent sound level in the various $\frac{1}{3}$-octave bands of the background noise in two conditions, measured at the ears of the subjects. Inserted is the hearing threshold of young listeners. 


\section{B. Apparatus}

The experiment was entirely computer controlled. The sounds were reproduced in the listening room by means of a loudspeaker (JBL-4425) hidden behind a curtain. The subjects were sitting behind a table furnished with a monitor and a keyboard. The distance between the listeners and the loudspeaker was about $3 \mathrm{~m}$. For frequencies above $100 \mathrm{~Hz}$, the reverberation time of the sound-insulated room was shorter than $0.5 \mathrm{~s}$. Hearing thresholds were determined with the help of a Madsen memory threshold audiometer (MTA 86) with the function switch in the auto-threshold mode with pulsating tones.

\section{Subjects}

Twelve normally hearing subjects (six males and six females) between 23 and 34 years of age participated in the experiment. The mean age was equal to 27.2 years; the standard deviation equaled 4.1 years. Before the experimental sessions, the hearing thresholds of the subjects were determined between 250 and $8000 \mathrm{~Hz}$ for the left- and right-hand ears separately. Ten subjects had hearing levels $\leqslant 10 \mathrm{~dB}$, and two subjects had hearing levels $\leqslant 15 \mathrm{~dB}$ in any part of the audiogram (best ears). The subjects were paid for their services.

\section{Procedure}

After hearing levels had been determined, the subjects were seated in the listening room. The subjects were tested individually. The appropriate background noise (Fig. 6) was present from the beginning of the sessions. The subjects were told that they were exposed to conditions in which traffic sounds (cars and trains passing by) could be heard either for the entire time period of $45 \mathrm{~s}$, or for a portion of this time period. The beginning and end of each 45-s condition was indicated on the monitor of their personal computer. After each condition the subjects responded to the question "How annoying would you find the sound in the preceding period if you were exposed to it at home on a regular basis?" They were instructed that while rating the sounds, they had to take into account everything that they heard in the 45-s time period. Moreover, they were encouraged to use the whole range of the rating scale with values from 0 ("not annoying at all") to 9 ("extremely annoying").

Six subjects started with the windows-open conditions, and the other six started with the windows-closed conditions. Before these experimental blocks, the subjects received six representative sound fragments to familiarize them with the differences among the conditions. Both in the training blocks and in the experimental blocks, the presentation order of the sound fragments was randomized. To enhance the reliability of the results, each condition was presented twice for rating in separate blocks.

For annoyance scores greater than 4 , both in the training block and in the second experimental block of each facade attenuation type, the subjects had to respond to five questions that informed about the causes of the expected annoyance. The preselected causes included were the perception of "loudness" (in Dutch: "luidheid") and other specific sound

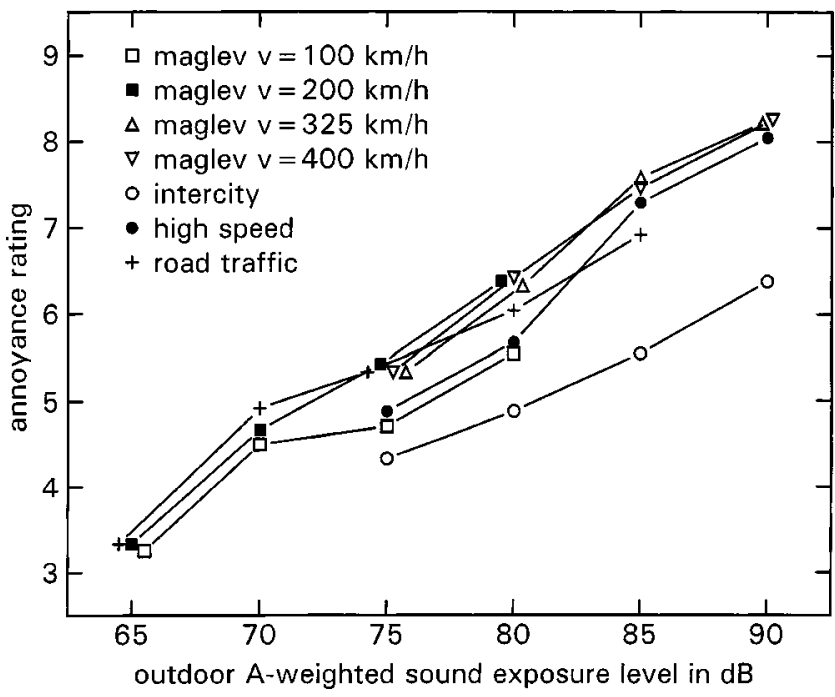

FIG. 7. Mean indoor annoyance ratings in the conditions which simulated open windows, for the various sound fragments as a function of the outdoor ASELs.

characteristics such as "heavily pounding" or "banging" (the Dutch word "bonkend" was used), and "squealing," "shrilly," or "squeaky" (the Dutch word "snerpend" was used). The other causes included were the feeling of "insecurity" or "unsafety" (in Dutch: "onveiligheid") and the reaction of "startle" (in Dutch: "schrik"). For each of these five questions, there were five response alternatives: quite correct, considerably correct, I don't know, not entirely correct, or not at all correct. In all conditions, the rating tasks were self-paced: The subjects were allowed to spend as much time for responding as they considered necessary.

\section{RESULTS}

As explained in Sec. I, the annoyance is related to outdoor levels, and the results are presented for the two facade attenuation types separately. The responses of the subjects were considered reliable if the correlation coefficients, $r$, computed between the first and second ratings for each subject separately, were higher than 0.5 . There was one subject who in the condition which simulated open windows did not fulfill this criterion. The data of the subject were replaced by those of a new subject with $r$-values that were considerably higher than the required criterion.

\section{A. Annoyance in the windows-open conditions}

The $r$-values, computed between the first and second ratings of the 29 sound fragments for each subject separately, ranged between 0.54 and $0.82(M=0.72, s . d .=0.09)$. Analyses of variance performed for the annoyance scores from three subsets of the data that are defined in Sec. III A 1, showed that the mean scores obtained in the first measurements were not significantly different from those obtained in the second measurements $(p>0.05)$, and that there were no significant first and second order interaction effects between replication and the stimulus variables $(p \geqslant 0.10)$. In the more detailed presentation of the results below, it was therefore decided to average across subjects and replications.

Figure 7 shows the annoyance scores, averaged across 
TABLE I. Annoyance ratings obtained in the conditions which simulated open windows. $M=$ mean annoyance ratings, $\sigma_{m}=$ standard error of the mean.

\begin{tabular}{|c|c|c|c|c|c|c|c|c|}
\hline \multirow[b]{2}{*}{ Sound source } & \multirow[b]{2}{*}{$V(\mathrm{~km} / \mathrm{h})$} & & \multicolumn{6}{|c|}{ Outdoor ASEL (dB) } \\
\hline & & & 65 & 70 & 75 & 80 & 85 & 90 \\
\hline \multirow[t]{8}{*}{ Maglev } & 100 & $M$ & 3.3 & 4.5 & 4.7 & 5.5 & $\ldots$ & $\ldots$ \\
\hline & & $\sigma_{m}$ & 0.31 & 0.32 & 0.29 & 0.26 & $\cdots$ & $\cdots$ \\
\hline & 200 & $M$ & 3.3 & 4.7 & 5.4 & 6.4 & $\ldots$ & $\ldots$ \\
\hline & & $\sigma_{m}$ & 0.32 & 0.29 & 0.30 & 0.28 & $\cdots$ & $\ldots$ \\
\hline & 325 & $M$ & $\ldots$ & $\cdots$ & 5.3 & 6.3 & 7.6 & 8.2 \\
\hline & & $\sigma_{m}$ & $\ldots$ & $\cdots$ & 0.28 & 0.30 & 0.21 & 0.22 \\
\hline & 400 & $M$ & $\ldots$ & $\cdots$ & 5.3 & 6.4 & 7.5 & 8.3 \\
\hline & & $\sigma_{m}$ & $\ldots$ & $\cdots$ & 0.27 & 0.23 & 0.26 & 0.20 \\
\hline \multirow[t]{2}{*}{ Intercity } & $120-140$ & $M$ & $\ldots$ & $\cdots$ & 4.3 & 4.9 & 5.5 & 6.4 \\
\hline & & $\sigma_{m}$ & $\cdots$ & $\cdots$ & 0.42 & 0.33 & 0.31 & 0.31 \\
\hline \multirow[t]{2}{*}{ High speed } & 300 & $M$ & $\ldots$ & $\cdots$ & 4.9 & 5.7 & 7.3 & 8.0 \\
\hline & & $\sigma_{m}$ & $\ldots$ & $\cdots$ & 0.39 & 0.34 & 0.27 & 0.27 \\
\hline \multirow[t]{2}{*}{ Road traffic } & 80 & $M$ & 3.3 & 4.9 & 5.3 & 6.0 & 6.9 & $\ldots$ \\
\hline & & $\sigma_{m}$ & 0.32 & 0.29 & 0.28 & 0.26 & 0.22 & $\cdots$ \\
\hline
\end{tabular}

subjects and replications, as a function of outdoor ASEL for each sound source separately. The mean values and the standard error of the mean are given in Table I.

In addition to main effects of ASEL and sound source, there was an interaction effect of these two variables. The statistical significance of these effects was tested in analyses of variance.

\section{Analyses of variance}

Data set $I$. The annoyance ratings for the road-traffic sounds and the sounds of the maglev train driving by at the two lower speeds, each presented at ASELs of 65, 70, 75, and $80 \mathrm{~dB}$, were subjected to an analysis of variance [12 $($ subjects $) \times 3$ (sound type $) \times 4$ (sound level) $\times 2$ (replication), all variables within subjects]. The ratings significantly increased with increasing sound level $[F(3,33)=82.0, p$ $<0.000001]$. The relatively small effect of sound type on the annoyance was just statistically significant $[F(2,22)$ $=3.7, p<0.05]$. The mean scores suggest that the increase in the annoyance with sound level was smaller for the maglev train passing by at a velocity of $100 \mathrm{~km} / \mathrm{h}$ than the increase obtained for the other two sound conditions. The interaction between sound type and sound level, however, was not significant $[F(6.66)=1.70, p>0.13]$.

Data set II. Next, the annoyance ratings for the sounds of the maglev train passing by at the two higher driving speeds and the annoyance ratings for the intercity and highspeed trains, each presented at ASELs of 75, 80, 85, and 90 $\mathrm{dB}$, were subjected to an analysis of variance [12 (subjects) $\times 4$ (sound type $) \times 4$ (sound level $) \times 2$ (replication), again with all variables within subjects]. The highly significant effect of sound level on the ratings found in the previous analysis was confirmed $[F(3,33)=63.0, p<0.000001]$. The ratings were also significantly affected by sound type $[F(3,33)=17.1, p<0.00001]$. This effect can be mainly ascribed to the relatively low annoyance ratings obtained for the intercity trains. The significant interaction between sound type and sound level $[F(9,99)=2.38, p<0.02]$ can be largely explained by the annoyance caused by the high-speed train: for lower ASELs of 75 and $80 \mathrm{~dB}$, its annoyance was in between that of the intercity train and the maglev train, whereas for the higher ASELs of 85 and $90 \mathrm{~dB}$, the annoyance was no longer different from that caused by the maglev train. An analysis of variance in which the annoyance ratings for the high-speed train were excluded, suggested that the difference in annoyance between the maglev train and the intercity-train sounds tended to increase with increasing ASEL $[F(6,66)=2.15, p<0.06]$.

Data set III. Inclusion of the annoyance ratings for road traffic in the analysis for ASELs of 75, 80, and $85 \mathrm{~dB}$ did not yield new information. In fact, of specific interest is the answer to the question whether the increase in the annoyance caused by the road-traffic sounds with increasing sound level is significantly less than that of the maglev-train sounds. The results of a separate analysis on the ratings for just these conditions showed that this interaction effect was not statistically significant $[F(4,44)=1.2, p>0.32]$. Moreover, this analysis showed that averaged across the three sound levels, there was no significant difference among the annoyance caused by the road-traffic sounds and the sounds of the maglev train passing by at the two different speeds $[F(2,22)$ $=2.1, p>0.14]$.

\section{Summary of the main effects}

Taking for granted the small and hardly significant difference in annoyance between (a) the sounds of the maglev train passing by at the speed of $100 \mathrm{~km} / \mathrm{h}$ and (b) the sounds of the maglev train passing by at the speed of $200 \mathrm{~km} / \mathrm{h}$ and the sounds of road traffic, three main conclusions may be drawn. At comparable ASELs (1) the annoyance was practically independent of the driving speed of the maglev train, (2) the annoyance caused by the maglev train was not different from the annoyance caused by road traffic, but (3) considerably higher than the annoyance caused by the intercity trains. The limited number of sound recordings of the highspeed train, together with the poor sound quality of one of these recordings that negatively affected the realistic character of two of the four sound fragments, do not allow us to draw firm conclusions about the annoyance caused by this sound source. 


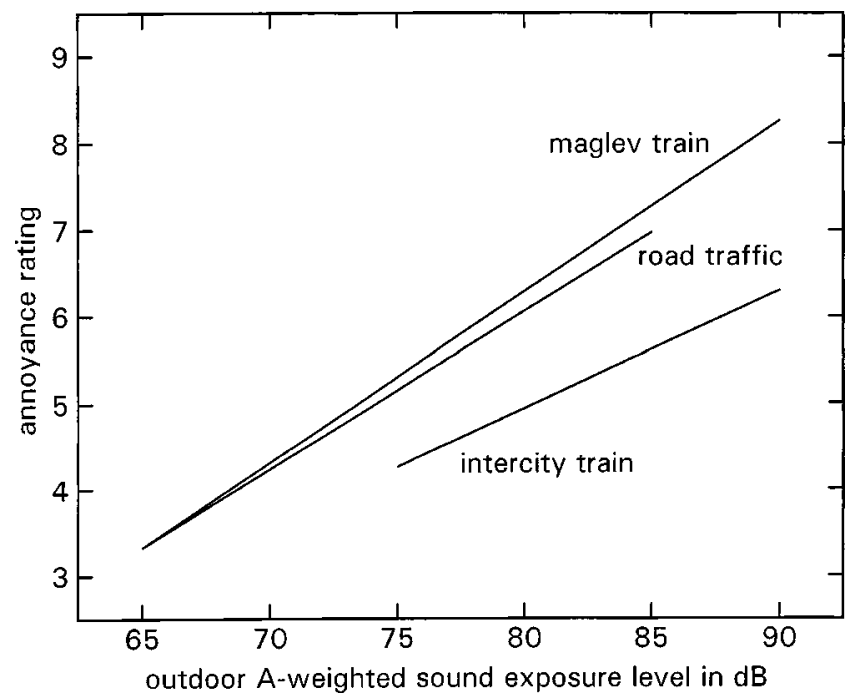

FIG. 8. Dose-response relations for maglev train, road traffic, and intercity train, in the conditions which simulated open windows. The solid lines are linear regression functions.

Figure 8 shows the three dose-response relations. The relations were obtained by linear fits of the 16 mean ratings for the maglev train $\left(y=-9.47+0.197 \mathrm{~L}_{\mathrm{AE}}, r=0.98\right)$, the five mean ratings for road traffic $\left(y=-7.14+0.166 \mathrm{~L}_{\mathrm{AE}}, r\right.$ $=0.98)$, and the four mean ratings for the intercity trains $\left(y=-5.95+0.136 \mathrm{~L}_{\mathrm{AE}}, r=0.995\right)$. The dose-response relation for the high-speed train (not shown in Fig. 8) is given by $y=-11.85+0.222 \mathrm{~L}_{\mathrm{AE}}(r=0.99)$.

With road traffic as the reference, Fig. 8 demonstrates that the bonus for the intercity trains varies from about $5 \mathrm{~dB}$ at $\mathrm{L}_{\mathrm{AE}}=75 \mathrm{~dB}$ to about $9 \mathrm{~dB}$ at $\mathrm{L}_{\mathrm{AE}}=90 \mathrm{~dB}$. The difference in annoyance between the two relevant train types can be quantified as well: The types are equally annoying if, dependent on sound level, the ASEL of the maglev-train passbysound is $5-10 \mathrm{~dB}$ lower than that of the intercity-train passby-sound.

\section{B. Annoyance in the windows-closed conditions}

The $r$-values, computed between the first and second ratings of the 29 sound fragments for each subject separately, ranged between 0.57 and $0.88(M=0.74, s . d .=0.09)$. Analyses of variance performed for the annoyance scores from three data sets defined in Sec. III B 1 showed that the mean scores obtained in the first measurements were not significantly different from those obtained in the second measurements $(p>0.85)$. In only one of the three subsets, there were small and hardly interpretable first order interaction effects between replication and the stimulus variables ( $p$ $\geqslant 0.02)$. For example, the second ratings for the sounds of the intercity train and the maglev train $(v=400 \mathrm{~km} / \mathrm{h})$ were slightly higher than the first ratings, whereas for the sounds of the high-speed train and the maglev train $(v$ $=325 \mathrm{~km} / \mathrm{h}$ ), the second ratings were slightly lower than the first ratings. Second order interaction effects between replication, sound level, and sound type were not significant ( $p$ $\geqslant 0.14)$. In the more detailed presentation of the results below, it was therefore decided to average across subjects and replications.

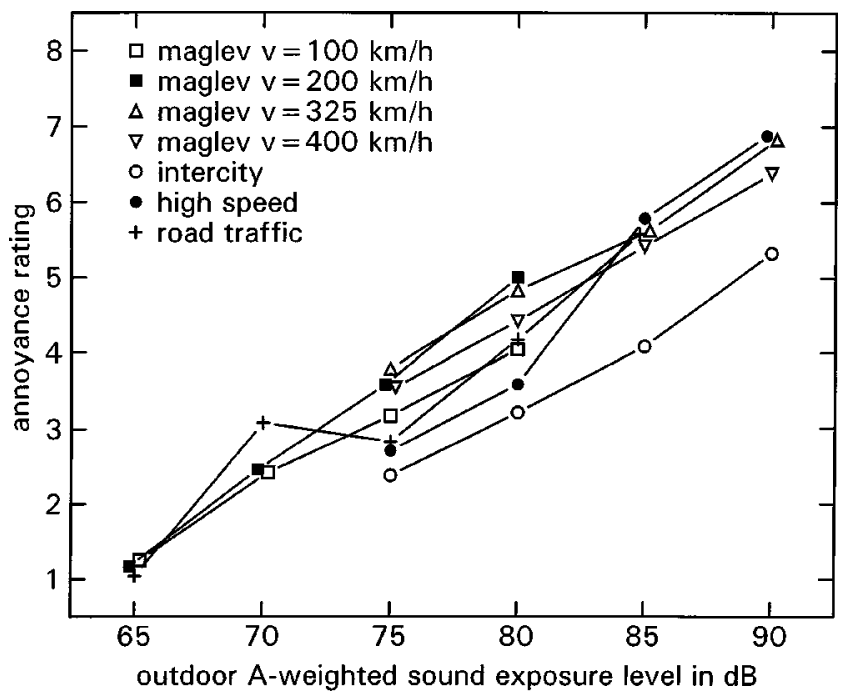

FIG. 9. Mean indoor annoyance ratings in the conditions which simulated closed windows, for the various sound fragments as a function of the outdoor ASELs.

Figure 9 shows the annoyance scores, averaged across subjects and replications, as a function of outdoor ASEL for each sound source separately. The mean values and the standard error of the mean are given in Table II.

Again, there were main and interaction effects of ASEL and sound source. The statistical significance of these effects was tested in analyses of variance.

\section{Analyses of variance}

Data set I. The annoyance ratings for the road-traffic sounds and the sounds of the maglev train driving by at the two lower speeds, each presented at ASELs of 65, 70, 75, and $80 \mathrm{~dB}$, were subjected to the same analysis of variance that had been used in Sec. III A 1 for data set I.

The ratings significantly increased with increasing sound level $[F(3,33)=88.2, p<0.000001]$. The effect of sound type on the ratings was not significant $[F(2,22)=1.1, p$ $>0.35]$. The interaction between sound type and sound level was statistically significant $[F(6.66)=3.27, p<0.007]$. This interaction effect is caused by the somewhat erratic relation between the annoyance ratings and sound level for the roadtraffic sounds presented at ASELs of 70 and $75 \mathrm{~dB}$. (In Sec. IV A, it will be explained that the unexpectedly high annoyance caused by the road-traffic sounds at $\mathrm{L}_{\mathrm{AE}}=70 \mathrm{~dB}$ is probably related to the casual presence of relatively much low-frequency energy in the truck passby sound.) An analysis of variance in which the annoyance ratings for the roadtraffic sounds were excluded showed that, for the maglevtrain sounds, the increasing difference in annoyance between the two driving speeds with sound level was not statistically significant $[F(3,33)=1.97, p>0.14]$.

Data set II. Next, the annoyance ratings for the sounds of the maglev train passing by at the two higher driving speeds and the annoyance ratings for the intercity and highspeed trains, each presented at ASELs of 75, 80, 85, and 90 $\mathrm{dB}$, were subjected to an analysis of variance with the design that has also been used in Sec. III A 1 for data set II. Again, the annoyance ratings were highly affected by sound level 
TABLE II. Annoyance ratings obtained in the conditions which simulated closed windows. $M=$ mean annoyance ratings, $\sigma_{m}=$ standard error of the mean.

\begin{tabular}{|c|c|c|c|c|c|c|c|c|}
\hline \multirow[b]{2}{*}{ Sound source } & \multirow[b]{2}{*}{$V(\mathrm{~km} / \mathrm{h})$} & & \multicolumn{6}{|c|}{ Outdoor ASEL (dB) } \\
\hline & & & 65 & 70 & 75 & 80 & 85 & 90 \\
\hline \multirow[t]{8}{*}{ Maglev } & 100 & $M$ & 1.3 & 2.4 & 3.2 & 4.0 & $\cdots$ & $\cdots$ \\
\hline & & $\sigma_{m}$ & 0.27 & 0.29 & 0.30 & 0.38 & $\cdots$ & $\cdots$ \\
\hline & 200 & $M$ & 1.2 & 2.5 & 3.6 & 5.0 & $\cdots$ & $\cdots$ \\
\hline & & $\sigma_{m}$ & 0.23 & 0.34 & 0.35 & 0.30 & $\cdots$ & $\cdots$ \\
\hline & 325 & $M$ & $\cdots$ & $\cdots$ & 3.8 & 4.8 & 5.6 & 6.8 \\
\hline & & $\sigma_{m}$ & $\cdots$ & $\cdots$ & 0.27 & 0.31 & 0.26 & 0.26 \\
\hline & 400 & $M$ & $\cdots$ & $\cdots$ & 3.5 & 4.4 & 5.4 & 6.4 \\
\hline & & $\sigma_{m}$ & $\cdots$ & $\cdots$ & 0.26 & 0.33 & 0.34 & 0.29 \\
\hline \multirow[t]{2}{*}{ Intercity } & $120-140$ & $M$ & $\cdots$ & $\cdots$ & 2.4 & 3.2 & 4.1 & 5.3 \\
\hline & & $\sigma_{m}$ & $\cdots$ & $\cdots$ & 0.31 & 0.31 & 0.32 & 0.34 \\
\hline \multirow[t]{2}{*}{ High speed } & 300 & $M$ & $\cdots$ & $\cdots$ & 2.7 & 3.6 & 5.8 & 6.9 \\
\hline & & $\sigma_{m}$ & $\cdots$ & $\cdots$ & 0.38 & 0.30 & 0.31 & 0.27 \\
\hline \multirow[t]{2}{*}{ Road traffic } & 80 & $M$ & 1.0 & 3.1 & 2.8 & 4.2 & 5.6 & $\ldots$ \\
\hline & & $\sigma_{m}$ & 0.29 & 0.40 & 0.36 & 0.35 & 0.34 & $\cdots$ \\
\hline
\end{tabular}

$[F(3,33)=99.6, p<0.000001]$. The effect of sound type was highly significant as well $[F(3,33)=18.3, \quad p$ $<0.000008]$. This effect can be mainly ascribed to the relatively low annoyance ratings for the intercity trains. The significant interaction between sound type and sound level $[F(9,99)=3.47, p<0.001]$ can be explained largely by the annoyance caused by the sounds from the high-speed train: for the lower ASELs of 75 and $80 \mathrm{~dB}$, the ratings were still close to those of the intercity-train sounds, whereas for the higher ASELs of 85 and $90 \mathrm{~dB}$, the ratings were almost equal to those for the maglev train.

Data set III. Inclusion of the annoyance ratings for road traffic in the analysis for ASELs of 75, 80, and $85 \mathrm{~dB}$ did not yield new information. As in Sec. III A 1, of specific interest is whether the increase in the annoyance caused by the roadtraffic sounds with increasing sound level was significantly less than that of the maglev-train sounds. The results of a separate analysis on the ratings for just these conditions showed that this interaction effect was not statistically significant $[F(4,44)=1.6, p>0.20]$. Moreover, this analysis showed that averaged across the three sound levels, there was no significant difference among the annoyance caused by the road-traffic sounds and the sounds of the maglev train passing by at the two different speeds $[F(2,22)=2.9$, $p>0.08]$.

\section{Summary of the main effects}

Again, three main conclusions may be drawn. At comparable outdoor ASELs (1) the annoyance was practically independent of the driving speed of the maglev train, (2) the annoyance caused by the maglev train was not different from the annoyance caused by road traffic, but (3) considerably higher than the annoyance caused by the intercity trains. Due to the imperfections noted in Sec. II A, it would be premature to draw firm conclusions about the annoyance caused by the high-speed train.

Figure 10 shows the three dose-response relations. The relations were obtained by linear fits of the 16 mean ratings for the maglev train $\left(y=-12.5+0.213 \mathrm{~L}_{\mathrm{AE}}, r=0.99\right)$, the five mean ratings for road traffic $\left(y=-11.9+0.203 \mathrm{~L}_{\mathrm{AE}}, r\right.$
$=0.96)$, and the four mean ratings for the intercity trains $\left(y=-12.3+0.194 \mathrm{~L}_{\mathrm{AE}}, r=0.995\right)$. The dose-response relation for the high-speed train (not shown in Fig. 10) is given by $y=-19.5+0.294 \mathrm{~L}_{\mathrm{AE}}(r=0.99)$.

With road traffic as the reference, Fig. 10 demonstrates that the bonus for the intercity trains is equal to about $5 \mathrm{~dB}$. In contrast with the results obtained in the conditions which simulated open windows, this bonus is independent of sound level. The difference in annoyance between the two relevant train types can be quantified as well: The types are equally annoying if the ASEL of the maglev-train passby sound is 6 $\mathrm{dB}$ lower than that of the intercity train passby sound.

\section{Causes of the expected annoyance}

As indicated in Sec. II D, the subjects had also been asked about the causes of their expected annoyance. Recall that the five questions were asked only (1) in the blocks in which the sound fragments were rated for the second time, and (2) if the annoyance score was greater than 4 . Collecting

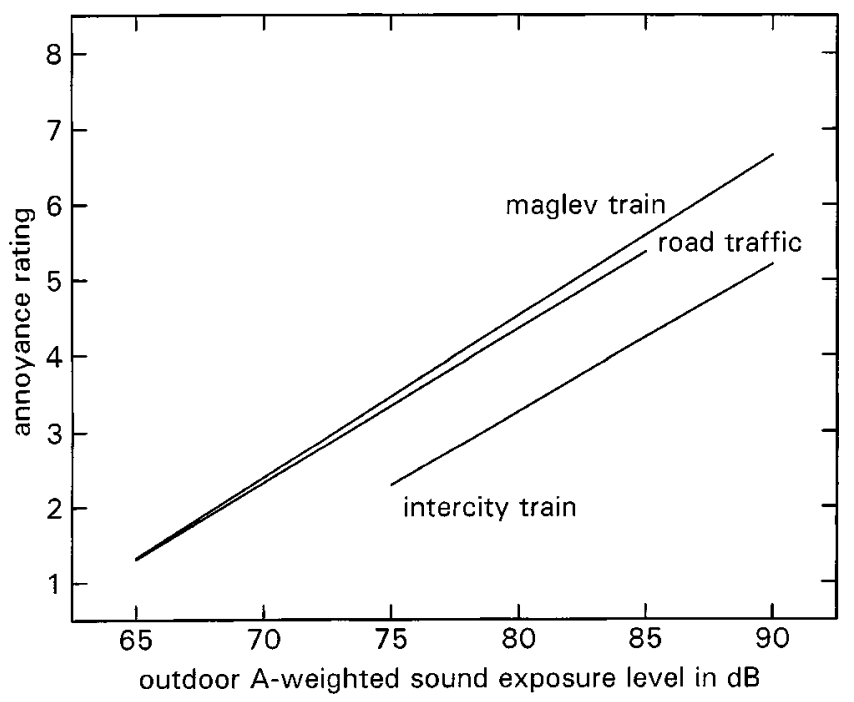

FIG. 10. Dose-response relations for maglev train, road traffic, and intercity train, in the conditions which simulated closed windows. The solid lines are linear regression functions. 
information about causes of the annoyance in conditions in which the subjects only expected to be a little or moderately annoyed was considered to be irrelevant.

Overall loudness. For all sound types loudness was selected as a cause of the annoyance. This was most prominent $^{2}$ for the sound fragments presented at the higher sound levels (outdoor $\mathrm{L}_{\mathrm{AE}} \geqslant 75 \mathrm{~dB}$ ) in the conditions which simulated open windows. In the conditions which simulated closed windows, a majority of the subjects had selected this cause only for the sound fragments that had been presented at, say, outdoor $\mathrm{L}_{\mathrm{AE}} \geqslant 85 \mathrm{~dB}$.

Specific sound characteristics. A heavily pounding sound as a general cause of the annoyance was frequently mentioned only for the high-speed train passby sound presented at the higher sound levels of 85 and $90 \mathrm{~dB}$. This held true both for the windows-open and for the windows-closed conditions. The shrilly sound character of a few passages of the maglev and the high-speed trains as a cause of the annoyance was chosen in the conditions which simulated open windows. In the windows-closed conditions, the shrillness of the sound was no longer an important cause of the annoyance, which can be understood from the effective facade attenuation of the pertinent high-frequency components.

Feeling of insecurity. In the conditions which simulated open windows, the majority of the subjects (with $n>6$ ) selected insecurity or unsafety as one of the causes of the annoyance resulting from the sounds of the maglev train (outdoor $\mathrm{L}_{\mathrm{AE}} \geqslant 85 \mathrm{~dB}$ ) passing by at velocities of 325 and 400 $\mathrm{km} / \mathrm{h}$. For the same sounds in the conditions which simulated closed windows, the relevance of the feeling of insecurity was much lower.

Startle. Independent of the facade attenuation type, the startle reaction to the sound as a cause of the annoyance was frequently mentioned in the conditions in which the ASEL of the sound of the maglev train passing by at a velocity of 325 or $400 \mathrm{~km} / \mathrm{h}$ was 85 or $90 \mathrm{~dB}$.

\section{DISCUSSION}

\section{A. Contribution of CSEL to the prediction of the annoyance}

In studies on the annoyance caused by impulse sounds produced by small, medium-large, and large firearms (Vos, 2001, 2003), it was shown that for conditions which simulated closed windows, the predictability of the indoor annoyance from outdoor ASELs was significantly improved by including the outdoor $\mathrm{C}$-weighted sound exposure level $\left(\mathrm{CSEL} ; \mathrm{L}_{\mathrm{CE}}\right)$ as a second variable. In these studies the difference between CSEL and ASEL ranged between about 0 and $30 \mathrm{~dB}$.

It is of interest to explore whether for the traffic sounds investigated in the present study, addition of CSEL would result in an increase of the predictability of the annoyance as well. For each sound fragment, the outdoor spectrum was estimated from the spectrum determined at the ears of the subjects in the conditions which simulated open windows (Figs. 2-5), by adding the corresponding frequencydependent facade attenuation (Fig. 1). These outdoor spectra allowed the calculation of ASEL and CSEL.
TABLE III. Difference between outdoor CSEL and ASEL in decibel, for various experimental conditions.

\begin{tabular}{|c|c|c|c|c|c|c|c|}
\hline \multirow[b]{2}{*}{ Sound source } & \multirow[b]{2}{*}{$v(\mathrm{~km} / \mathrm{h})$} & \multicolumn{6}{|c|}{ Outdoor ASEL (dB) } \\
\hline & & 65 & 70 & 75 & 80 & 85 & 90 \\
\hline \multirow[t]{4}{*}{ Maglev } & 100 & 5.9 & 5.8 & 5.8 & 5.5 & $\cdots$ & $\ldots$ \\
\hline & 200 & 3.9 & 4.0 & 4.0 & 4.2 & $\ldots$ & $\ldots$ \\
\hline & 325 & $\ldots$ & $\ldots$ & 3.3 & 3.3 & 3.3 & 3.5 \\
\hline & 400 & $\ldots$ & $\ldots$ & 3.0 & 3.1 & 3.1 & 3.1 \\
\hline Intercity & $120-140$ & $\ldots$ & $\ldots$ & 1.3 & 1.0 & 0.7 & 0.0 \\
\hline High speed & 300 & $\ldots$ & $\ldots$ & 0.7 & 0.7 & 7.1 & 7.1 \\
\hline Road traffic & 80 & 8.1 & 13.8 & 3.3 & 4.5 & 3.5 & ... \\
\hline
\end{tabular}

Table III shows the differences between CSEL and ASEL for all 29 conditions. For the sounds of the maglev train passing by at speeds of $100,200,325$, and $400 \mathrm{~km} / \mathrm{h}$, the difference $\mathrm{L}_{\mathrm{CE}}-\mathrm{L}_{\mathrm{AE}}$ was independent of $\mathrm{ASEL}$ and equal to about $6,4,3$, and $3 \mathrm{~dB}$, respectively. For the sounds of the intercity trains $\mathrm{L}_{\mathrm{CE}}-\mathrm{L}_{\mathrm{AE}}$ was equal to about $1 \mathrm{~dB}$. For the high-speed train, $\mathrm{L}_{\mathrm{CE}}-\mathrm{L}_{\mathrm{AE}}$ was equal to $1 \mathrm{~dB}$ for the sound fragments that were presented at ASELs of 75 and $80 \mathrm{~dB}$, and equal to $7 \mathrm{~dB}$ for the other sound fragments. Due to the selective application of the high-pass filter to the first two sound fragments, however, the validity of the differences among these $\mathrm{L}_{\mathrm{CE}}-\mathrm{L}_{\mathrm{AE}}$ values must be questioned.

As a result of the small differences between CSEL and ASEL, as found for the sounds from the maglev and intercity trains, it is unlikely or even impossible that addition of CSEL as a second variable would lead to a significant and unequivocally interpretable improvement of the annoyance prediction. $^{3}$

For the road-traffic sounds the differences $\mathrm{L}_{\mathrm{CE}}-\mathrm{L}_{\mathrm{AE}}$ ranged between 3 and $14 \mathrm{~dB}$ (see Table III). In Sec. II A, it was explained that the sound fragments presented at ASELs of 65 and $70 \mathrm{~dB}$, included passby sounds recorded at a distance of $60 \mathrm{~m}$ from the road, and that the sound fragments presented at ASELs of 75 and $80 \mathrm{~dB}$ included passby sounds recorded at a distance of $25 \mathrm{~m}$. It should be emphasized that the passby sounds used in the various sound fragments had not been recorded simultaneously. As a result, in addition to recording distance (and sound level), the fragments may also be different with respect to the individual vehicles passing by. Moreover, even the fragments presented at ASELs of 65 and $70 \mathrm{~dB}$ did not exactly consist of the same components.

Figure 11 shows that as a result of this procedure, the sound fragment presented at $\mathrm{L}_{\mathrm{AE}}=70 \mathrm{~dB}$ contains much more energy in the $63-\mathrm{Hz} \frac{1}{3}$-octave band than the sound fragment presented at $\mathrm{L}_{\mathrm{AE}}=75 \mathrm{~dB}$. This low-frequency energy has a considerable effect on CSEL only. The spectral difference shown in Fig. 11 is caused by inclusion of different trucks. The overall spectral contents of the various passenger cars in the two sound fragments were almost equal.

The somewhat erratic relation between the annoyance ratings and sound level for the road-traffic sounds in the condition which simulated closed windows (Fig. 9) can in part be explained by the corresponding $\mathrm{L}_{\mathrm{CE}}-\mathrm{L}_{\mathrm{AE}}$ values. This was confirmed in a multiple linear regression analysis. By adding $\mathrm{L}_{\mathrm{CE}}-\mathrm{L}_{\mathrm{AE}}$ as a second predictor of the mean annoyance ratings, the explained variance in the ratings signifi- 


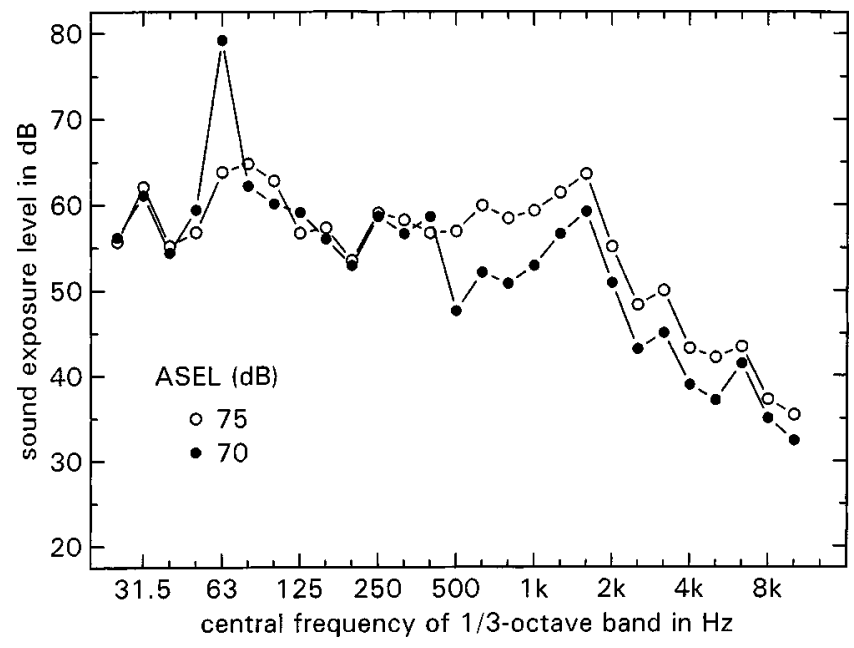

FIG. 11. Sound exposure levels in the various $\frac{1}{3}$-octave bands for roadtraffic sounds, as determined at the ears of the subjects in two conditions which simulated open windows. The spectra correspond to overall outdoor ASELs as indicated.

cantly $(p<0.02)$ increased from $91.0 \%$ to $99.7 \%$. In a similar regression analysis performed on the ratings obtained in the conditions which simulated open windows (Fig. 7), addition of $\mathrm{L}_{\mathrm{CE}}-\mathrm{L}_{\mathrm{AE}}$ as a second variable did not result in a significant $(p>0.19)$ increase in the predictability of the annoyance. This is consistent with the findings reported in Vos (2001).

\section{B. Railway bonus}

Both in the windows-open and in the windows-closed conditions, the annoyance caused by the intercity trains was considerably lower than that caused by road traffic, provided that the ASELs were the same. Averaged across the two facade attenuation types, the bonus for the intercity trains was equal to about $6 \mathrm{~dB}$. Support for a railway bonus has been found in field surveys conducted more than 20 years ago (e.g., see Heimerl and Holzmann, 1979; Schümer-Kohrs et al., 1981; Knall and Schümer, 1983; Fields and Walker, 1982). From the dose-response relationships for road-traffic and railway sounds obtained in a recent meta-analysis (Miedema and Oudshoorn, 2001), it can be revealed that for A-weighted day-night levels between 50 and $70 \mathrm{~dB}$, the railway bonus varies between 5 and $8 \mathrm{~dB}$.

Figure 12 shows the railway bonus as a function of the day-night level of railway sounds for three different annoyance measures given in Miedema and Oudshoorn (2001). The lower curve in Fig. 12 was derived from the relationships with the community response expressed as the percentage of respondents who were at least a little annoyed (LA). The two higher curves in Fig. 12 were derived from the relations with the response expressed as the percentages of respondents who were at least moderately (MA) or at least highly annoyed (HA). It can be concluded that the railway bonus is only slightly affected by the day-night level and the annoyance measure, and that $6 \mathrm{~dB}$ is the typical value.

As a result, the bonus for the intercity trains obtained in the present experiment corresponds well with the mean bonus found in field surveys for residential areas with moderate

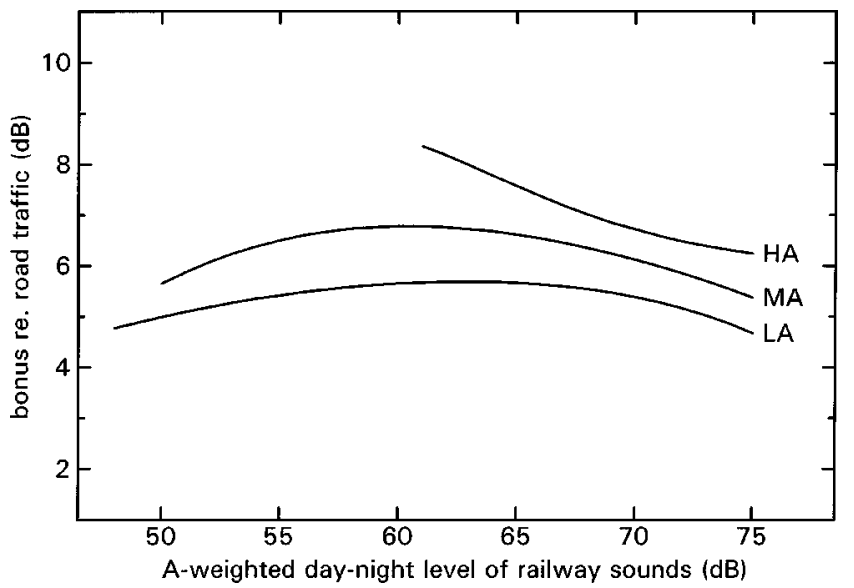

FIG. 12. Railway bonus derived from dose-response relationships reported in Miedema and Oudshoorn (2001), as a function of the day-night level of railway sounds, for three different annoyance measures.

to high exposure levels. It should be emphasized that in contrast with the preliminary loudness data reported in Fastl and Gottschling (1996) and in Gottschling and Fastl (1997), the results of the present experiment do not support application of such a bonus to the maglev-train sounds.

The satisfying correspondence between the railway bonuses obtained in our experiment and in various field surveys supports the validity of the present laboratory study. One might argue that the 6-dB bonus is merely the result of specific features of the experimental method or the sound fragments. One such feature might be the stimulus duration, affecting ASEL of the two sources in a different way. However, it is unlikely that a change in stimulus duration would affect the size of the bonus, as can be understood from the following argument.

For the same density of the road-traffic sounds, a doubling of the stimulus duration results in a 3-dB increase in ASEL. With still one passage of the intercity train, a doubling of the total stimulus duration (i.e., the relevant rating period) has no effect on its ASEL. Relative to the condition with the shorter duration, the annoyance caused by the roadtraffic sounds with the longer stimulus duration may be expected to remain the same. The annoyance caused by the railway sound, however, is expected to decrease as a result of the favorably judged large increase of the time period without noise (Vos, 1992a, b; Vos and Geurtsen, 1992, 1995). If this decrease in annoyance is equal to the change in annoyance produced by a $3-\mathrm{dB}$ shift in the sound exposure level of the intercity train, there will be no change in the previous railway bonus at all.

Again for the same density of the road-traffic sounds, halving of the stimulus duration (from 45 to $22.5 \mathrm{~s}$ ) results in a 3-dB decrease in ASEL. With still a single passage of the intercity train, halving of the total stimulus duration has no effect on its ASEL. Relative to the condition with the longer duration, the annoyance caused by the road-traffic sounds may be expected to remain the same. The annoyance caused by the railway sound, however, is expected to increase as a result of the lack of the favorably rated quiet period. Once more, if this increase in annoyance is equal to the change in annoyance that results from a $3-\mathrm{dB}$ increase in the sound 
exposure level of the intercity train, the railway bonus in this hypothetical stimulus configuration will be equal to the bonus obtained in the present experiment.

\section{Issues for future research}

In Sec. IV B it was shown that there is sufficient support for a bonus for the more conventional railway sounds. Although at present there is little direct evidence of the reasons for this railway bonus (e.g., see Fields and Walker, 1982), the more plausible explanations may have to do with the relatively long quiet periods between passbys, as mentioned in Sec. IV B, and with attitudinal variables such as "fear" and "importance" (Fields, 1993; Miedema and Vos, 1999). Both a low fear level associated with railways (trains do not fall out of the sky or run into people's houses) and a strong belief that the railways are economically or otherwise important for the local area or some broader community might reduce the annoyance.

In the present laboratory study, the annoyance caused by the maglev-train sounds was higher than the annoyance caused by the sounds from the intercity trains. It might be hypothesized that this effect is at least in part due to the fact that our listeners were not familiar ${ }^{4}$ with the maglev train. With the passage of time, residents could potentially develop positive attitudes toward maglev trains, resulting in a decrease of the difference in annoyance between the two train types. For example, information about various measures of precaution might reduce fear and, subsequently, noise annoyance. For exploring the contribution of the nonacoustic factors described above, ${ }^{5}$ the present experiment should be enlarged, amongst other things by providing information about the various sound sources and by accompanying the sounds with realistic images of the passing vehicles and trains.

\section{v. CONCLUSIONS}

At equal outdoor A-weighted sound exposure levels, (1) the annoyance was virtually independent of the speed of the maglev-train passages, (2) the annoyance caused by the maglev-train passby sounds was hardly different from the annoyance caused by the road-traffic sounds, and (3) the annoyance caused by the intercity train passages was considerably lower than that caused by the maglev-train and roadtraffic sounds. These results (4) held true both for open and for closed windows.

Moreover, it was concluded that (5) the sounds might be expected to be equally annoying if the outdoor sound levels of the maglev-train passbys are at least $5 \mathrm{~dB}$ lower than those of the intercity train passbys, (6) the differences between the outdoor C-weighted and A-weighted sound exposure levels were too small for expecting a significant increase in the predictability of the annoyance by adding this difference in sound level as a second variable, and (7) in addition to perceived loudness, startle reactions and feelings of insecurity might play a role in the annoyance caused by the sounds of the maglev train.

\section{ACKNOWLEDGMENTS}

This research was financed by Project Group Zuyderzeeline (Ministry of Transport, Public Works, and Water Management, and Ministry of Housing, Spatial Planning, and the Environment), The Netherlands. The author is grateful to Keith Wilson for his comments on an earlier draft of this paper.

${ }^{1}$ More information can be obtained on www.dot.gov/affairs/maglevbg.htm and other websites.

${ }^{2}$ For example, restricting ourselves to those conditions in which more than 6 of the 12 subjects had answered the questions, loudness had been indicated as one of the causes of the annoyance in $80 \%-100 \%$ of the cases.

${ }^{3}$ For the total set of 29 conditions, the annoyance increased with increasing outdoor ASEL and increasing $\mathrm{L}_{\mathrm{CE}}-\mathrm{L}_{\mathrm{AE}}$. By addition of $\mathrm{L}_{\mathrm{CE}}-\mathrm{L}_{\mathrm{AE}}$ as a second predictor of the annoyance, the explained variance slightly but significantly increased by 4 percent points in the condition which simulated open windows, and by 5 percent points in the condition which simulated closed windows. Separate analyses performed on the ratings for the 16 maglev train sounds only, however, showed that in the windows-closed listening mode, addition of $\mathrm{L}_{\mathrm{CE}}-\mathrm{L}_{\mathrm{AE}}$ did not lead to a significant improvement of the predictions $(p>0.14)$, and in the windows-open listening mode it led to an improvement in the explained variance as small as one percent point $(p<0.02)$. Moreover, in both listening modes, the regression weight for $\mathrm{L}_{\mathrm{CE}}-\mathrm{L}_{\mathrm{AE}}$ was negative, implying that the annoyance would decrease with increasing $\mathrm{L}_{\mathrm{CE}}-\mathrm{L}_{\mathrm{AE}}$, which is in contrast with the previous results.

${ }^{4}$ Our subjects were told that they were exposed to sounds of passing cars and trains. Although they were not explicitly asked to identify the source of the maglev-train sounds, there is no reason to believe that they would not have been able to assign the maglev-train sounds to the category of "railwaylike" sounds. In spite of the fact that, just as our participants, none of the subjects in the studies reported by Fastl and Gottschling (1996) and by Gottschling and Fastl (1997) had heard the maglev-train sounds before, all of them had identified the sounds as "train noise." Identifying the maglevtrain sounds as "train noise," however, does not mean that our subjects were familiar with these sounds to the same degree as they are with the more conventional intercity trains.

${ }^{5}$ More issues for additional research are described in the minutes of the Expert Meeting "Annoyance caused by maglev trains," held on February 27th 2003 at TNO Human Factors in Soesterberg, The Netherlands. For a copy of these minutes, the reader is referred to www.zuiderzeelijn-info.nl. de Graaff, E., Holties, H., Kurze, U. J., Martner, O., Meißner, F. H., and Nürnberger, H. (2001). Acoustical research on maglev train for the Zuiderzeelijn, Report No. 50694/2, M+P Raadgevende Ingenieurs, Den Bosch, The Netherlands, and Müller-BBM, Planegg, Germany.

Fastl, H., and Gottschling, G. (1996). "Subjective evaluation of noise immissions from Transrapid," in Proceedings Internoise 1996 (Liverpool, UK), Vol. 4, pp. 2109-2114.

Fields, J. M. (1993). "Effect of personal and situational variables on noise annoyance in residential areas," J. Acoust. Soc. Am. 93, 2753-2763.

Fields, J. M., and Walker, J. G. (1982). "Comparing the relationships between noise level and annoyance in different surveys: a railway vs. aircraft and road traffic comparison," J. Sound Vib. 81, 51-80.

Gottschling, G., and Fastl, H. (1997). "Akustische Simulation von 6-Sektionen-Fahrzeugen des Transrapid," [Acoustical simulation of 6-section-vehicles of the Transrapid] in Fortschritte der Akustik-DAGA 1997 (Bad Honnef, Germany), DPG-GmbH, pp. 254-255.

Heimerl, G., and Holzmann, E. (1979). "Ermittlung der Belästigung durch Verkehrslärm in Abhängigkeit von Verkehrsmittel und Verkehrsdichte in einem Ballungsgebiet (Straßen- und Eisenbahnverkehr)," [Determination of the annoyance caused by traffic noise as a function of transportation system and traffic density in the area of population concentration (road and railroad traffic)] Kampf dem Lärm 26, 64-69.

Knall, V., and Schümer, R. (1983). "The differing annoyance levels of rail and road traffic noise," J. Sound Vib. 87, 321-326.

Miedema, H. M. E., and Oudshoorn, C. G. M. (2001). "Annoyance from 
transportation noise: relationships with exposure metrics DNL and DENL and their confidence intervals," Environ. Health Perspect. 109(4), 409416.

Miedema, H. M. E., and Vos, H. (1999). "Demographic and attitudinal factors that modify annoyance from transportation noise," J. Acoust. Soc. Am. 105, 3336-3344.

Neugebauer, D., and Ortscheid, J. (1997). "Geräuschbewertung des Transrapid," [Noise evaluation of the Transrapid] in Fortschritte der AkustikDAGA 1997 (Bad Honnef, Germany), DPG-GmbH, pp. 403-404.

Quehl, J. (1999). "Schienenbonus für Transrapid?-Eine semantische Klanguntersuchung zur Uebertragbarkeit des Schienenbonus auf die Magnetschnellbahn," [Railway bonus for Transrapid-A semantic investigation of timbre regarding the application of the railway bonus to the maglev] Z. Lärmbekämpfung 46(5), 163-174.

Schümer-Kohrs, A., Schümer, R., Knall, V., and Kasubek, W. (1981). "Vergleich der Lästigkeit von Schienen- und Straßenverkehrslärm in städtischen und ländlichen Regionen," [Comparison of annoyance by railway and road traffic noise in urban and rural areas] Z. Lärmbekämpfung 28, 123-130.

Versfeld, N. J., and Vos, J. (1997). "Annoyance caused by sounds of wheeled and tracked vehicles," J. Acoust. Soc. Am. 101(5), Part 1, 26772685.

Versfeld, N. J., and Vos, J. (2002). "A-weighted equivalent sound level as a predictor of the annoyance caused by road traffic consisting of various proportions of light and heavy vehicles," J. Sound Vib. 253(2), 389-399.

Vos, J. (1992a). "Noise annoyance around irregularly employed shooting ranges: the expected effect of various training schedules," in Proceedings of the 6th International FASE Congress 1992 (Swiss Acoustical Society, Zürich, Switzerland), pp. 355-358.

Vos, J. (1992b). "Annoyance caused by low frequency sounds from artillery fire: the expected effect of various training schedules," J. Low Freq. Noise Vib. 11(2), 47-51.

Vos, J. (1995). "A review of research on the annoyance caused by impulse sounds produced by small firearms," in Proceedings Internoise 1995, Newport Beach, CA, Vol. 2, pp. 875-878.

Vos, J. (2001). "On the annoyance caused by impulse sounds produced by small, medium-large, and large firearms," J. Acoust. Soc. Am. 109, $244-$ 253.

Vos, J. (2003). "A- and C-weighted sound levels as predictors of the annoyance caused by shooting sounds, for various facade attenuation types," J. Acoust. Soc. Am. 113, 336-347.

Vos, J., and Geurtsen, F. W. M. (1992). Geluidhinder rond onregelmatig gebruikte schietbanen: een studie naar het verwachte effect van verschillende tijdschema's [Noise annoyance around irregularly employed shooting ranges: the expected effect of various training schedules], Report IZF 1992 A-13, TNO Human Factors, Soesterberg, The Netherlands.

Vos, J., and Geurtsen, F. W. M. (1995). Geluidhinder rond onregelmatig gebruikte schietbanen: een vervolgstudie naar het verwachte effect van concentratie van schietactiviteiten op de hinder [Noise annoyance around irregularly employed shooting ranges: a further study on the expected effect of concentration of training activities on annoyance], Report TNO-TM 1995 A-44, TNO Human Factors, Soesterberg, The Netherlands. 